\title{
A IMPORTÂNCIA DOS PRINCÍPIOS DA PEDAGOGIA FREIRIANA PARA ORIENTAÇÃO DOS ESTÁGIOS CURRICULARES SUPERVISIONADOS NO CURSO DE PEDAGOGIA
}

\author{
Lucimara Cristina de Paula \\ Universidade Estadual de Ponta Grossa (UEPG), Ponta Grossa, Paraná, \\ Brasil
}

\begin{abstract}
RESUMO: Neste artigo são apresentadas algumas discussões e resultados da primeira etapa de uma pesquisa qualitativa em andamento, de caráter bibliográfico (LIMA; MIOTO, 2007; SALVADOR, 1978), orientada pelos seguintes objetivos: investigar, nas construções teóricas e nas ações dialógicas do "método de alfabetização" de Paulo Freire, contribuições para a organização didática dos estágios curriculares supervisionados no curso de Pedagogia e sistematizar orientações teóricas e práticas para os estágios curriculares supervisionados, numa perspectiva problematizadora e crítica a partir da práxis freiriana. Os resultados apontam alguns princípios fundamentais da pedagogia freiriana para as orientações das docências durante os estágios: a curiosidade, a criticidade, a relação leitura de mundo-leitura da palavra, a pesquisa, a dialogicidade.
\end{abstract}

Palavras-chave: Formação inicial. Pedagogia. Estágio Supervisionado. Paulo Freire.

\section{INTRODUÇÃO}

Ao retomar a análise dos princípios que embasam o ensino na Lei de Diretrizes e Bases da Educação Nacional, Lei 9394/96, algumas provocações emergem, a partir de desafios ainda não superados historicamente, como a igualdade de condições para o acesso e permanência na escola, o pluralismo de ideias e concepções pedagógicas, a valorização dos profissionais da educação, a gestão democrática do ensino público, a garantia de padrão de qualidade. Situação preocupante quando observamos, passadas duas décadas da promulgação da lei, que cerca de dois milhões de crianças e jovens brasileiros estão fora das escolas; que mais de $50 \%$ das crianças que finalizam o $3^{\circ}$ ano do Ensino Fundamental, na rede pública do Brasil, apresentam níveis insuficientes de leitura e matemática; que o movimento "Escola sem partido" ameaça a discussão livre e crítica das formas de opressão, exploração, discriminação e manipulação; ao constatarmos a histórica e crescente precariedade das condições de trabalho e de salário dos professores brasileiros, bem como o autoritarismo vigente nas relações profissionais dentro das escolas e sistemas de ensino; e ainda a fragmentação curricular e a ausência 
de um projeto político pedagógico construído democrática e conscientemente nas escolas.

Tais desafios, entre outros, já estão colocados para os futuros professores e professoras, pedagogos e pedagogas, em seus cursos de licenciatura, no momento de seus estágios curriculares supervisionados, ao se defrontarem com a imensa responsabilidade que envolve as tarefas de educar, ensinar, relacionar-se, coordenar ações, gerir questões administrativas, formar-se continuamente, pesquisar o próprio trabalho e aproximar-se das culturas que adentram as redes públicas de ensino. $O$ estágio é o espaço privilegiado de confronto dialético entre a formação teórica e a vivência da prática pedagógica no campo profissional, em que as capacidades de planejar, analisar e avaliar terão início, gerando desconforto, frustração, descontentamento, mas, também, a oportunidade do (a) estagiário (a) verificar a própria transformação e a transformação dos outros, decidindo se deseja de fato, ou não, seguir a trajetória como profissional da educação.

Embora represente um espaço de aprendizagens relevantes e de grande impacto na formação inicial dos(as) futuros(as) pedagogos(as), não é possível desconsiderar as limitações e dilemas enfrentados por estudantes e professores(as) formadores(as) durante os estágios, materializados nas dificuldades inerentes ao estabelecimento de uma relação, com sentido, entre teoria e prática, em diferentes momentos: na ação e reflexão de planejar e avaliar, considerando a relação educador(a)conhecimento-aluno(a) que ocorre por meio da linguagem e dos contextos; na construção da própria posição como futuro(a) educador(a), que vive a contradição entre o que é discutido na universidade e o que é verificado na escola; no confronto estudante-experiência (observação e docência)-professor(a) orientador(a) e professor(a) da escola; na habilidade de pesquisar e pensar criticamente suas posições e concepções.

$O$ enfrentamento dessas dificuldades e dilemas se reflete com intensidade nos estágios, mas não está desarticulado de um preparo inadequado dos profissionais do ensino durante o curso de formação, que mantém um formato tradicional (BRASIL, 2001). O Parecer CNE/CP009/2001, sobre as Diretrizes Curriculares Nacionais para a Formação de Professores da Educação Básica em nível superior, já denunciava as lacunas dos cursos de formação, que não contemplavam características demandadas à atividade docente na atualidade, como o comprometimento com o sucesso da aprendizagem dos alunos, a necessidade de assumir e saber lidar com a diversidade existente entre eles, o desenvolvimento de práticas investigativas e hábitos de colaboração e trabalho em equipe, saber orientar e mediar o ensino para a aprendizagem dos(as) alunos(as), entre outras.

Construir essas características na articulação entre universidades e escolas não constitui uma tarefa simples para formadores(as), estudantes e profissionais dos contextos escolares, que necessitam de tempo, muitas discussões fundamentadas e diálogo para engajarem-se no processo de pensar a própria formação e a formação de outras pessoas (crianças, jovens e adultos), assumindo posicionamentos éticos favoráveis à criação de espaços e grupos comprometidos com as dimensões técnica e política do processo educativo. 
PAULA, L. C. de

O Parecer 009/2001 alerta ainda para o problema do desconhecimento que as equipes de formação têm sobre o repertório de conhecimentos e experiências dos(as) estudantes, pois já passaram muitos anos dentro de contextos escolares e alguns já exercem a docência, como no caso do Paraná, que ainda mantém o curso de Magistério em nível médio. Portanto, eventuais deficiências advindas da formação discente na educação básica, assim como a falta de profundidade na compreensão dos conteúdos e temas transversais ao currículo, que serão objeto de sua ação didática, deverão ser discutidas dentro das universidades para a definição de encaminhamentos que supram as limitações identificadas.

Para a formação do licenciado em Pedagogia é central o conhecimento da escola como uma organização complexa que tem a função social e formativa de promover, com eqüidade, educação para e na cidadania. É necessário que saiba, entre outros aspectos, que entre os povos indígenas, a escola se constitui em forte mecanismo de desenvolvimento e valorização das culturas étnicas e de sustentabilidade econômica, territorial das comunidades, bem como de articulação entre as organizações tradicionais indígenas e o restante da sociedade brasileira.

Também é central, para essa formação, a proposição, realização, análise de pesquisas e a aplicação de resultados, em perspectiva histórica, cultural, política, ideológica e teórica, com a finalidade, entre outras, de identificar e gerir, em práticas educativas, elementos mantenedores, transformadores, geradores de relações sociais e étnico-raciais que fortalecem ou enfraquecem identidades, reproduzem ou criam novas relações de poder. (BRASIL, 2015).

Em decorrência das demandas por conhecimentos sobre a escola como organização complexa, que desempenha importante função social e formativa, por conhecimentos e procedimentos pedagógicos e científicos que contribuam para a identificação e elaboração de práticas educativas transformadoras, que redimensionem as relações sociais, fortalecendo as identidades étnico-raciais e desconstruindo relações de poder, e em virtude das limitações formativas dos(as) estudantes ao chegarem no ensino superior e de suas formas tradicionais de trabalho educativo, salienta-se o grande potencial dos estágios curriculares supervisionados como momento de aprendizagens fundantes para a docência.

Embora as Diretrizes Curriculares Nacionais para o Curso de Graduação em Pedagogia (2006) apresentem, em seu Artigo 50, um conjunto de dezesseis exigentes aptidões para o egresso do curso, o percurso traçado pelos estágios poderá ser edificante o suficiente para desenvolver competências relacionadas ao desempenho profissional e à contextualização curricular, preparando para a vida cidadã (BRASIL, 2008).

Apostar nos estágios como momento fundamental para o desenvolvimento de um perfil profissional de educador(a) comprometido com a formação integral dos seres humanos, favorável à superação das desigualdades, respeitando as diferentes manifestações culturais nas relações humanas e no trabalho com os conteúdos, promovendo situações de expressão cultural em diversas linguagens de forma criativa e crítica, superando todo o tipo de preconceito e optando pela solidariedade nas relações, 
ao invés de processos educativos competitivos e individualistas, motivou o desenvolvimento desta pesquisa na busca por uma formação problematizadora e crítica durante os estágios curriculares supervisionados, pautada na perspectiva progressista freiriana.

A pesquisa, iniciada no ano de 2017, ainda não está concluída e seus dados ainda estão sendo organizados, analisados e aplicados na disciplina de Estágio Curricular Supervisionado em Docência nos Anos Iniciais do Ensino Fundamental, oferecida aos (às) estudantes do $4^{\circ}$. ano de Pedagogia, em uma universidade pública no Estado do Paraná. A disciplina possui carga horária anual de 102 horas, sendo que 51 horas são dedicadas aos estudos e discussões teórico-práticos na universidade e as outras 51 horas são destinadas às atividades na escola: 30 horas para observações do trabalho pedagógico e escolar e 21 horas para o exercício das docências em uma turma dos anos iniciais do Ensino Fundamental de escolas da rede pública municipal.

Durante o desenvolvimento da disciplina, os princípios da pedagogia freiriana têm fundamentado as orientações para o planejamento didático das ações em sala de aula e o posicionamento das (os) estudantes nas relações com os (as) alunos(as) das escolas. Esses princípios representam construções teóricas que embasam a práxis do educador Paulo Freire em toda a sua produção escrita e na sistematização de seu "método de alfabetização" de adultos.

Neste artigo, devido ao espaço delimitado para sua extensão, serão apresentados os princípios que fundamentam as orientações oferecidas aos (às) estudantes para os estágios curriculares supervisionados, pois os registros sobre como ocorreram as ações pautadas nas orientações ainda estão em processo de análise. Esses registros encontram-se no diário de acompanhamento das docências dos (as) estudantes, escrito pela professora da disciplina; nos diários de observação das (os) estagiárias (os) sobre o trabalho pedagógico realizado pelas professoras das escolas públicas e nas narrativas de autoavaliação que esses (as) estagiários (as) escreveram sobre suas experiências como docentes, durante as 21 horas em que atuaram como professores(as). Ao todo, foram reunidos os registros de 30 estudantes estagiários (a), entre os anos de 2017 e 2018.

\section{O IMPACTO DOS ESTÁGIOS NA FORMAÇÃO DOS (AS) ESTUDANTES DE PEDAGOGIA}

Ao realizar o trabalho de orientação e acompanhamento das (os) estudantes de Pedagogia durante os Estágios Curriculares Supervisionados em Docência na Educação Infantil e nos Anos Iniciais do Ensino Fundamental, no ano de 2016, foi possível constatar que esse momento do curso de formação oferece profundos desafios e experiências impactantes no processo de constituição da identidade docente das (os) futuras (os) educadoras (es). O impacto que o momento do estágio oferece à formação das (os) licenciandas(os) foi evidenciado em trabalhos de conclusão de curso por Silva (2016) e Dambroski (2016), que também motivaram a realização desta pesquisa. Naquele ano, os estudos sobre Paulo Freire estavam sendo introduzidos na disciplina.

O trabalho de Silva (2016) revelou que os estágios curriculares supervisionados constituíram uma experiência de grande importância para a formação das(os) 
pedagogas(os), pois se destacaram como uma oportunidade em que podem formar os outros e serem formadas(os), sentindo-se professoras e professores, conquistando aprendizagens, compartilhando experiências e saberes, podendo se aproximar e conhecer melhor as peculiaridades da Educação Infantil e do Ensino Fundamental, tornando as crianças protagonistas do trabalho educativo.

Ao vivenciarem essa etapa do processo de formação, as (os) acadêmicas(os) puderam refletir profundamente sobre os diferentes aspectos do processo educativo, como o planejamento, as relações entre cuidar e educar, a apropriação das diferentes linguagens, a consideração da leitura de mundo que as crianças constroem, a imprescindível relação entre a teoria e a prática, a necessidade de problematizar o contato das crianças com o mundo, recusando uma educação bancária (SILVA, 2016). Além disso, os estágios propiciaram olhares críticos sobre o trabalho educativo das escolas que, muitas vezes, geravam conflitos entre as propostas e conhecimentos discutidos no âmbito da universidade e os procedimentos, posicionamentos e valores evidenciados nos contextos escolares.

Essas diferenças apontaram para a necessidade de diálogo e parceria respeitosos entre as equipes que representavam a universidade e as escolas, traçando um caminho de trabalho compartilhado em que todas as pessoas envolvidas poderiam se assumir como educadoras e educandas.

Por sua vez, o trabalho de Dambroski (2016) evidenciou que o estágio curricular supervisionado, oferecido no curso de Pedagogia, se mostrou tão relevante para as pessoas que já possuíam formação anterior como docentes, no curso de Magistério, quanto para as pessoas que estavam sendo formadas para a docência na universidade. As contribuições valiosas para a aprendizagem da docência foram se conformando por meio da prática pedagógica orientada na disciplina, que possibilitou a atuação na realidade escolar com embasamento teórico freiriano, discutido ao longo da disciplina de Estágio Curricular Supervisionado, assim como oportunizou o acompanhamento de processos de ensinar e aprender e a reflexão compartilhada sobre eles.

Os estudos de Dambroski (2016) destacaram que o Estágio Curricular Supervisionado permitiu compreender as especificidades da escola e da prática e pensar estratégias para mobilização do interesse dos alunos na realização de ações, respeitando suas particularidades, amparando-se em rigorosa fundamentação teórica.

Tanto os estudos acadêmicos das alunas, como a produção científica de pesquisadores e pesquisadoras sobre o estágio curricular supervisionado, além da experiência de orientar e acompanhar as diferentes ações desenvolvidas durante a disciplina de estágio no curso de Pedagogia, apontam para o enfrentamento de inúmeros desafios que se colocam quando optamos por uma formação pedagógica, técnica e política das (os) futuras(os) educadoras(es). Afinal, a possibilidade de contribuir para a transformação dos contextos escolares e transformar-se ao inserir-se neles, dependem de muitas variáveis. Entre elas, a estrutura do curso e da disciplina de estágio, a carga horária disponível para realizar ações e verificar seus resultados, as relações entre a universidade, as escolas e os sistemas de ensino, as diferentes formas de compreender os processos educativos etc.

Além disso, no decorrer das experiências de formação, é preciso que a(o) estagiária(o) saiba investigar questões específicas de sua área de conhecimento, pesquisando a si mesma(o), a fim de que tenha condições de projetar o próprio trabalho, 
avaliando seu desempenho e contribuindo para o crescimento dos(as) alunos(as) (FAZENDA, 2001); que os cursos superem a dicotomia entre teoria e prática; que o conhecimento da realidade escolar, por meio dos estágios, favoreça reflexões sobre uma prática criativa e transformadora, possibilitando a reconstrução ou redefinição de teorias que sustentem o trabalho das(os) professoras(es) (PICONEZ, 2001).

Entretanto, trabalhar para a superação desses e outros desafios, desenhando caminhos para uma formação que articule criticidade, rigorosidade metódica, ética, pesquisa e comprometimento político (FREIRE, 2014) para uma educação de qualidade para todas as pessoas, exige que a realidade do ensino e os (as) educandos(as) sejam vistos como mutáveis, como históricos e sociais e, portanto, passíveis de transformação, no sentido de não reproduzirem as diferentes formas de desigualdade. Nesse sentido, 0 estágio necessita ser um espaço de questionamento crítico dos modelos de ensino observados nos contextos escolares, de busca do conhecimento científico e do entendimento sobre a complexidade que envolve as situações do exercício profissional, evitando a redução do profissional ao "prático" (PIMENTA e LIMA, 2011).

De acordo com Pimenta e Lima (2011), os estágios são atividades teóricas que instrumentalizam a práxis docente, considerada como transformação da realidade, pois envolvem fundamentação, diálogo e intervenção na realidade. As autoras anunciam a possibilidade de encaminhar os estágios como pesquisa, considerando o conhecimento não como verdade capaz de explicar toda e qualquer situação, mas a busca do novo conhecimento na relação entre as explicações existentes e os novos dados que a realidade impõe.

Por outro lado, os estudos de Aroeira (2014) apontam amplas possibilidades para a aprendizagem docente por meio de um estágio colaborativo com a escola, firmando redes coletivas de trabalho para a formulação de práticas interdisciplinares.

Refletir sobre a formação docente implica conceber a perspectiva de coformação e assumir que o estágio não é responsável por promover a práxis de um curso de formação de professores, mas, quando este considera práticas de partilha com a escola, aspectos de colaboração e reflexividade, assim como de pesquisa e de interdisciplinaridade, pode cumprir de modo institucional, numa perspectiva emancipatória, a função de colaborar num processo formativo a favor da unidade teoria e prática. (AROEIRA, 2014, p. 145-146).

Considerar todas essas demandas para os estágios curriculares supervisionados, como oportunidade de articulação entre a teoria e a prática, voltada a uma ação intencional e comprometida politicamente com a educação pública, por meio de relações dialógicas entre acadêmicas(os) estagiárias(os) e instituições formadoras é, portanto, uma tarefa complexa que implica pensar quais teorias e práticas defendemos, quais compromissos assumimos com aqueles(as) que se encontram todos os dias nas escolas públicas e que forma de dialogar permeia nossas relações. Implica pensar em quais abordagens teóricas e práticas nos debruçamos e quais compromissos defendemos como educadoras e educadores, considerando a favor de quem e contra 
quem atuamos, e que tipo de mudanças sociais sonhamos construir com nosso trabalho; implica também uma postura ética e política, que nos mova em direção a determinados objetivos no plano educativo.

Paulo Freire (2003, 2004, 2005 e 2014) indica caminhos de esperança e luta, raiva e amor, conhecimento crítico e transformação, que nos direcionam para ações educativas pautadas na força das relações intersubjetivas, numa perspectiva dialógica, que oferece visões mais abrangentes sobre os processos sociais e formativos nos quais nos inserimos. Tais caminhos tornam-se urgentes em tempos de intenso conservadorismo, sustentado por ações repressivas e ideológicas que tencionam silenciar e imobilizar aqueles e aquelas que desejam e atuam pela diminuição das desigualdades.

Nesse sentido, a produção teórico-prática de Paulo Freire oferece possibilidades para a organização de ações emancipadoras de formação docente pautadas nas relações dialéticas entre subjetividade-objetividade, humanização-desumanização, transformação-adaptação, denúncia e anúncio, ação cultural-invasão cultural, educação bancária-educação problematizadora, leitura de mundo-leitura da palavra, docênciadiscência.

Ao tratar da importância do trabalho de Freire para a construção de um trabalho pedagógico crítico, que provoque o desvelamento das relações entre cultura e poder, vislumbrando as escolas como espaços possíveis de produção de conhecimento anti-hegemônico, Apple (2017, p. 51) afirma que "sua vida pode ter acabado, mas seu legado permanece vivo entre todos nós que exigimos justiça".

Na perspectiva progressista de Freire (2003, 2004, 2005 e 2014), não é possível dicotomizar a formação científica da aprendizagem que se dá pelo corpo consciente, a formação técnica do posicionamento político, o ensino dos conteúdos do conhecimento de experiência feito, a prática de ensinar da curiosidade para aprender, a formação permanente da reflexão crítica sobre a prática, a disponibilidade para o diálogo da convicção da possibilidade da mudança. Sobre as contribuições que a pedagogia progressista de Freire oferece para o processo de constituição das futuras educadoras e futuros educadores, durante as experiências de estágio na formação inicial, podem-se destacar as considerações dos estudos de Dambroski (2016) e Silva (2016):

Sobre os estudos da pedagogia de Paulo Freire, estes contribuíram para compreender que, para ensinar, são necessárias algumas exigências, como perceber que a criança é o sujeito do processo, que é necessário saber ouvi-las e pensar em atividades que partam da leitura de mundo das crianças, reconhecendo que elas têm sentimentos e vontades e que vivem diferentes contextos. Cabe às educadoras e educadores, permitir que elas expressem suas opiniões e, através de suas falas e gestos, pensar em estratégias para atingir os objetivos propostos para a aula, permitindo que elas construam e reconstruam os conhecimentos. Realizar um trabalho contemplando essas especificidades permite promover uma educação problematizadora e libertadora, o que é o contrário de uma educação bancária e autoritária. (DAMBROSKI, 2016, p.82).

Tiveram destaque principal neste trabalho as contribuições de Paulo Freire (1991, 1992, 2015), por nos ajudar a compreender e pensar o estágio na Educação Infantil sob uma perspectiva do 
diálogo, do respeito ao educador e ao educando, da práxis, da pesquisa, da conscientização, da reflexão, da problematização e da formação permanente dos professores e formadores. Enfim, esse autor nos ajudou a ter uma postura política e progressista diante das ações pedagógicas, tanto no momento da elaboração da pesquisa quanto no momento em que o estágio acontecia. (SILVA, 2016, p.101, grifo do autor)

Ao desenvolver um pensamento comprometido com a vida, com a existência humana (FIORI, 2004), Paulo Freire se tornou um grande projeto coletivo, repensado, recriado e reconstruído por inúmeros (as) educadores (as) em todas as partes do mundo, nas escolas, universidades, movimentos sociais e organizações comunitárias (ANDREOLA, 2001). A atualidade de seu pensamento é afirmada pela realidade social e cultural que o alimentou e que ainda continua viva; tempos de brutal desumanização das camadas populares, nos quais assistimos a diferentes formas de exclusão e opressão que se alastram mediante a globalização, o que demanda entendimento da dramaticidade que a envolve (ARROYO, 2001).

Nesse contexto, torna-se imprescindível compartilhar a pertinência do legado de Paulo Freire para as atividades de ensino, pesquisa e extensão na universidade, apropriando-se dele para 0 trabalho com os estágios curriculares supervisionados durante a formação inicial no curso de Pedagogia.

\section{OS CAMINHOS METODOLÓGICOS DA PESQUISA}

No intuito de planejar caminhos para uma formação ética, crítica, problematizadora, humana, rigorosa cientificamente e comprometida com as crianças que frequentam as escolas públicas, durante os estágios curriculares supervisionados do curso de Pedagogia, foram delineados os seguintes objetivos para a primeira etapa da pesquisa:

a) Investigar, nas construções teóricas e nas ações dialógicas do "método de alfabetização" de Paulo Freire, contribuições para a organização didática dos estágios curriculares supervisionados no curso de Pedagogia;

b) Sistematizar orientações teóricas e práticas para os estágios curriculares supervisionados, numa perspectiva problematizadora e crítica, a partir da práxis freiriana.

A pesquisa é de natureza qualitativa, de caráter bibliográfico e exploratóriodescritivo, construída por meio de um conjunto ordenado de procedimentos para a busca de soluções, tendo em vista o objeto de estudo e os objetivos propostos (LIMA e MIOTO, 2007). A opção metodológica se justifica pela investigação de um objeto de conhecimento encontrado em fontes bibliográficas (livros).

Enquanto pesquisa qualitativa, este estudo considera que a temática estudada apresenta algumas especificidades:

- É histórica, pois está situada temporalmente e, portanto, pode ser transformada; 
- Possui consciência histórica, na medida em que outras pessoas the atribuem sentido a partir das relações estabelecidas socialmente;

- É intrínseca e extrinsecamente ideológica ao veicular visões de mundo construídas historicamente e resistir às limitações colocadas pelos esquemas de dominação existentes (MINAYO, 2000).

Nesta perspectiva, o processo de pesquisa se constitui numa atividade científica que alimenta e atualiza a atividade de ensino frente à realidade, ao provocar a indagação e reconstrução dessa realidade. Por outro lado, articula pensamento e ação, pois toma como objeto de conhecimento um problema da vida prática (LIMA e MIOTO, 2007).

A qualificação de um estudo que estabelece a pesquisa bibliográfica como procedimento metodológico depende de alguns cuidados essenciais:

- Apresentação das concepções e ações relacionadas à apreensão da realidade, que expressam uma visão social, de mundo e de ser humano, utilizada na interpretação das interações pessoas-realidade;

- Grande alcance de informações que permite o uso de dados dispersos em publicações, auxiliando na construção, ou melhor, na definição do quadro conceitual que envolve o objeto de estudo;

- Detalhamento do processo de coleta e análise dos dados.

Os procedimentos metodológicos obedecem a uma sequência que compreende quatro fases, que compõem um processo contínuo, no qual cada etapa pressupõe aquela que a precede e se completa na seguinte, conforme as orientações de Salvador (1986):

a) Formulação do problema de pesquisa e elaboração de um plano para a busca de respostas às questões formuladas;

b) Coleta da documentação: levantamento bibliográfico e levantamento das informações contidas na bibliografia;

c) Análise crítica da documentação, a fim de explicar ou justificar as informações relacionadas ao material;

d) Síntese integradora, que representa o produto final do trabalho, como resultado da análise e reflexão sobre os documentos. Esse produto compreende as atividades que envolvem a apreensão do problema, a investigação rigorosa e a visualização de soluções.

As leituras sucessivas do material configuram técnicas ${ }^{1}$ para a obtenção de informações em cada momento da pesquisa:

a) Leitura de reconhecimento do material bibliográfico: para localizar e selecionar os materiais que podem apresentar informações ou dados referentes ao tema;

b) Leitura exploratória: para verificar se as informações encontradas nas obras são relevantes, de acordo com os objetivos propostos;

c) Leitura seletiva: para selecionar os materiais diretamente relacionados aos objetivos da pesquisa;

d) Leitura reflexiva ou crítica: para ordenar e sumarizar as informações selecionadas, buscando compreender os conceitos construídos pelo autor;

e) Leitura interpretativa: para estabelecer relações entre os conceitos expressos nas obras e o problema delimitado (SALVADOR, 1986). 
A rigorosa disciplina na execução de cada leitura garante a consistência na análise do material, o que proporciona um vasto e rico campo de possibilidades de novos temas ainda não explorados. Tratando-se da obra de Paulo Freire, construída por meio de relações dialéticas entre conceitos que se articulam a outros conceitos, formando uma rede conceitual complexa e abrangente, a leitura em profundidade exigiu uma leitura reflexiva que permitisse identificar cada princípio teórico na constituição dessa rede conceitual, que é continuamente retomada pelo autor ao explicar um novo conceito. Por isso, o trabalho de identificação, classificação e contextualização dos princípios, feito a partir de trechos esclarecedores sobre eles, foi artesanal e possibilitado pelas sucessivas idas e vindas pelas páginas dos livros: Pedagogia da autonomia (2018), Pedagogia da esperança (2003), À sombra desta mangueira (2005), Pedagogia do oprimido (2004), A importância do ato de ler (2011) e Medo e ousadia (2003), escrito em parceria com Ira Shor.

\section{PRINCÍPIOS FREIRIANOS FUNDAMENTAIS PARA A FORMAÇÃO DOCENTE DURANTE OS ESTÁGIOS}

O estudo criterioso das obras escritas por Paulo Freire (2003, 2004, 2005 e 2014), em diferentes momentos históricos, ofereceu importantes princípios para a formação de docentes numa perspectiva progressista, isto é, comprometida com a educação de todos (as) os(as) educandos(as), preocupada com a máxima qualidade da aprendizagem dos conteúdos, de forma problematizadora, crítica, curiosa, investigativa, respeitadora das diferenças entre as pessoas, dialógica e solidária. Esses princípios foram discutidos sistematicamente nas aulas e orientações para a prática pedagógica, ocorridas durante a disciplina de Estágio Curricular Supervisionado em Docência nos Anos Iniciais do Ensino Fundamental do curso de Pedagogia de uma universidade pública do Estado do Paraná, nos anos de 2017 e 2018. Tais princípios propiciaram transformações nas formas de conceber os(as) educandos(as), o papel do(a) educador(a), as relações entre educadores(as) e educandos(as), o tratamento dos conteúdos em relação dialética com a leitura de mundo das crianças, a importância do desenvolvimento da curiosidade e da problematização, assim como representou mudanças na forma de compreender os processos de ensino e aprendizagem, o uso da linguagem e a necessidade de pesquisar de forma séria e profunda os conteúdos que constituirão objeto de conhecimento entre professores(as) e alunos(as).

De maneira sintética, são apresentados os principais fundamentos:

1. Leitura de mundo e leitura da palavra: Paulo Freire (2003 e 2015) entende que $\mathrm{o}$ ato de ler não se restringe à decifração da palavra escrita. A linguagem escrita deve ser precedida pela leitura de mundo, pois a leitura do texto não pode constituir uma ruptura com a leitura do contexto. Nesse sentido, o conhecimento de experiência feito deve ser - ponto de partida para uma leitura mais crítica, científica, totalizadora, problematizadora de mundo, superando a consciência ingênua por meio da verificação de que as verdades são provisórias, que os seres humanos são históricos, sociais e culturais e, portanto, modificam sua própria realidade. Para Freire (2003), a leitura e a escrita de textos devem acompanhar a análise dos contextos para uma releitura do mundo. 
PAULA, L. C. de

2. Educação problematizadora: se a realidade não pode ser abordada como algo estático, compartimentado e bem-comportado, também não poderá ser compreendida por meio da dissertação de assuntos alheios à experiência existencial dos seres humanos. Enquanto sujeitos cognoscentes do processo educativo, educadores (as) e educandos (as) se debruçam sobre o objeto a ser conhecido, perguntando-se sobre ele, buscando apropriar-se dele em suas diferentes dimensões, como seres inconclusos, inacabados, incompletos. Ao exercerem o ato de conhecer, educadores (as) e educandos (as) reconhecem-se como seres históricos pela comunicação, co-intencionados ao objeto de suas reflexões, compartilhando significados e tecendo acordos sobre ele. Essa prática de conhecer em comunhão, na relação entre leitura de mudo e leitura da palavra, possibilita a superação de equívocos na forma como conheciam antes. Juntos, podem admirar melhor algo que admiraram antes (FREIRE, 2004, 2003; FREIRE; SHOR, 2003).

3. Curiosidade: de acordo com Freire (2018), os procedimentos autoritários negam a curiosidade, silenciam os (as) educandos (as) em seu processo de aprender e, da mesma forma, representam o silenciamento do educador (a) frente ao seu próprio processo de aprender a ensinar. A curiosidade é um direito dos seres humanos, que os insere na busca pela razão de ser dos fatos, negando a domesticação, a memorização mecânica de conteúdos que burocratizam a mente, pois evita a aproximação metódica com o objeto a ser conhecido. A curiosidade estimula a pergunta, a expressão de conhecimentos, a reflexão, a contraposição de olhares sobre aquilo que instiga quem olha, por meio da comunicação (FREIRE; SHOR, 2003). A curiosidade e a indagação mobilizam a pergunta e o diálogo, conduzindo à pesquisa rigorosa dos fatos. Ao abolir o espaço para manifestação da curiosidade, os (as) educadores (as) atrofiam a liberdade e o direito de saber mais, de ser mais, matando a criatividade, a capacidade de produzir conhecimentos.

4. Criticidade: para Freire (2018) não existe entre a ingenuidade e a criticidade, entre o saber de pura experiência feito e os saberes metodicamente rigorosos, uma ruptura, mas uma superação, pois a curiosidade ingênua, sem deixar de ser curiosidade, vai se tornando crítica. Ao deixar de ser ingênua para tornar-se crítica, a curiosidade se faz epistemológica em sua aproximação com o objeto, para levantar achados de maior exatidão. Nesse sentido, a curiosidade nos move como inquietação indagadora, como busca do desvelamento de algo, como problematização, como procura de esclarecimentos, que promovem a criticidade. Na educação bancária não é possível ser crítico, pois não é possível exercer a curiosidade, a pergunta, a compreensão maior da razão de ser dos fatos (FREIRE, 2004).

5. Pesquisa: ensinar é uma ação que exige pesquisa, assim como a pesquisa não se faz sem o ensino (FREIRE, 2014).

Enquanto ensino continuo buscando, reprocurando. Ensino porque busco, porque indaguei, porque indago e me indago. Pesquiso para constatar, constatando, intervenho, intervindo educo e me educo. Pesquiso para conhecer o que ainda não conheço e comunicar ou anunciar a novidade. (FREIRE, 2014, p. 3031).

No ciclo gnosiológico, pensar certo representa tanto o respeito ao senso comum, no processo de sua superação, quanto o respeito e o estímulo à capacidade 
criadora dos (as) educandos (as). "Implica o compromisso da educadora com a consciência crítica do educando, cuja 'promoção' da ingenuidade não se faz automaticamente" (FREIRE, 2014, p. 31). Estudar, pesquisar, conhecer, exige disciplina, rigorosidade na interpretação da realidade, sem racismo científico, ou seja, sem negar esse ou aquele autor, essa ou aquela abordagem porque lhe fazem alguma crítica.

6. Dialogicidade: o diálogo freiriano é ação-reflexão, é práxis. Portanto, é palavra verdadeira, é coerência entre o que se diz e o que se faz. Se a palavra é destituída de sua dimensão da ação, ela se transforma em verbalismo, tornando-se alienada e alienante, fazendo-se oca, sem comprometimento. Por outro lado, se a ênfase é dada à ação, com sacrifício da reflexão, a palavra se converte em puro ativismo. E se palavra é práxis, açãoreflexão, para transformação das pessoas e do mundo, não poderá ser privilégio apenas de algumas pessoas, negando a outras o direito de pronúncia do mundo (FREIRE, $2004 \mathrm{e}$ 2005). Por meio do diálogo, os seres humanos adentram de forma curiosa, crítica, indagadora, rigorosa e respeitosa no objeto que as mediatiza, conhecendo melhor o que antes conheciam, em comunhão com os outros (FREIRE, 2005).

Todos esses princípios não se encontram separados nas obras de Freire, mas amalgamados numa rede de significados que explicam os processos de ensinoaprendizagem numa perspectiva progressista, que representa a oportunidade de conscientizar-se no diálogo com os outros. Por isso, não é possível compreendê-los de forma fragmentada, delimitada, pontual.

Outros princípios, além desses, foram levantados, analisados e sistematizados como orientações para os estágios curriculares supervisionados, marcando as diferenças entre uma educação bancária e uma educação problematizadora, como: a escuta atenta e reflexiva dos alunos, o respeito à diversidade, o estabelecimento de relações democráticas, a criatividade, a disponibilidade para a mudança, a reflexão sobre a prática, entre outros. Entretanto, a exposição de cada princípio não caberia na extensão deste artigo.

Esses princípios ofereceram fundamentação para a construção de um roteiro de orientações, que subsidiaram o planejamento das aulas oferecidas às turmas dos anos iniciais pelas (os) estagiárias (os) durante as 21 horas que dispunham para as atividades de docência, assim como também orientaram suas ações pedagógicas. $O$ empenho em seguir tais orientações, contrariando as práticas silenciadoras e bancárias observadas em sala de aula, provocou aprendizagens marcantes nas (os) estudantes durante a realização dos estágios, que foram compartilhadas com as (os) colegas do $4^{\circ}$ ano de Pedagogia na forma de seminários. Os registros sobre essas aprendizagens ainda estão sendo analisados. No entanto, é possível apresentar um esboço sobre eles.

\section{ALGUMAS CONSIDERAÇÕES}

Durante os momentos de orientação das (os) estudantes para as docências desenvolvidas com as crianças dos anos iniciais do Ensino Fundamental, como exigência para o cumprimento dos estágios curriculares supervisionados no curso de Pedagogia, os princípios freirianos foram discutidos como ações a serem assumidas no desenvolvimento dos conteúdos, a partir da discussão sobre o planejamento das aulas. 
O planejamento constituiu um termômetro a respeito de como as (os) estagiárias (os) concebiam o processo de ensino-aprendizagem, possibilitando discussões sob um olhar crítico a respeito da elaboração das aulas, materiais, procedimentos didáticos, conhecimento do conteúdo, características da turma de crianças e os valores assumidos.

Por meio de uma discussão detalhada, entre as (os) estagiárias (os) e a professora orientadora dos estágios, sobre cada parte do planejamento e sobre as concepções presentes nas práticas que o compunham, as (os) estudantes puderam compreender as relações entre os princípios freirianos e o desenvolvimento de ações pedagógicas de natureza progressista e se propuseram a refletir e reorientar suas ações junto aos alunos dos anos iniciais. Para isso, tiveram o acompanhamento atento da orientadora que observava as aulas de cada estagiária (o) e orientava respeitosamente cada ação.

Após a finalização das docências, as (os) estudantes apresentaram seminários às (aos) suas (seus) colegas, a fim de exporem as aprendizagens marcantes adquiridas nas relações com as crianças, a partir dos princípios freirianos. Dentre as principais aprendizagens, podemos destacar: dar ouvidos às crianças, não as subestimando, a fim de melhor conhecê-las e conhecer seus contextos; valorizar os conhecimentos dos alunos, estimulando a participação de todos na discussão e exploração dos conteúdos, de forma democrática; relacionar o conhecimento de experiência feito dos alunos com o conhecimento científico de forma interdisciplinar e com os acontecimentos regionais e globais; respeitar as diferenças culturais e sociais, sendo consciente de que, no papel de professor(a), deve sempre buscar saber mais; pesquisar profundamente os conteúdos para abordá-los de forma abrangente, preparando-se para responder a dúvidas; exercitar o diálogo, estimulando a curiosidade, a criatividade e a criticidade das crianças; optar por ações que desenvolvam a cooperação, buscando romper com o individualismo e a competitividade; ter responsabilidade ética, política e profissional, comprometendo-se com a própria formação; e ampliar os referenciais de mundo das crianças, trabalhando pela superação das desigualdades.

É possível que essas aprendizagens venham a sucumbir diante da aderência das (os) futuras (os) professoras (es) à forma de organização e funcionamento das escolas, e na ausência de um trabalho pedagógico construído mediante cooperação entre professores pesquisadores da universidade e professores iniciantes. Esse novo desafio será objeto das próximas etapas desta pesquisa.

Artigo recebido em: 30/01/2019

Aprovado para publicação em: 30/04/2019

THE IMPORTANCE OF THE PRINCIPLES OF PEDAGOGY FREIRIANA FOR ORIENTATION OF SUPERVISED TRAINEESHIPS IN THE COURSE OF PEDAGOGY

ABSTRACT: In this article are presented some discussions and results of the first stage of a qualitative research in progress, of bibliographical character (LIMA; MIOTO, 2007; SALVADOR, 1986) which is driven by these objectives: investigate, in theoretical constructions and dialogical 
actions of "literacy method" of Paulo Freire, contributions to the didactic organization of curricular traineeships supervised in the course of pedagogy and systemize theoretical and practical guidelines for supervised traineeships, in a problematinzing and critical perspective from the Praxis freiriana. The results show some fundamental principles of the freiriana pedagogy to the subjects guidelines during the traineeships: curiosity, criticality, the realtion of reading worldword, the research, the dialogue.

KEYWORDS: Initial training. Pedagogy. Supervised Internship. Paulo Freire.

\section{LA IMPORTANCIA DE LOS PRINCIPIOS DE LA PEDAGOGÍA FREIRIANA PARA ORIENTACIÓN DE LAS PASANTÍAS CURRICULARES SUPERVISIONADAS EN EL CURSO DE PEDAGOGÍA}

RESUMEN: En ese artículo son presentadas algunas discusiones y resultados de la primera etapa de una pesquisa cualitativa en andamiento, de carácter bibliográfico (LIMA; MIOTO, 2007; SALVADOR, 1986) la cual es orientada por los objetivos: investigar, en las construcciones teóricas y en las acciones dialógicas del "método de alfabetización" de Paulo Freire, contribuciones para la organización didáctica de las pasantías curriculares supervisionadas en el curso de Pedagogía y sistematizar orientaciones teóricas y prácticas para las pasantías curriculares supervisionadas, en una perspectiva problematizadora y crítica a partir de la práxis freiriana. Los resultados apuntan algunos principios fundamentales de la pedagogía freiriana para las orientaciones de las docencias durante las pasantías: la curiosidad, la criticidad, la relación lectura de mundo-lectura de la palabra, la pesquisa, la dialogicidad.

PALABRAS CLAVE: Formación inicial. Pedagogía. Pasantía Supervisionada. Paulo Freire.

NOTA

1) Essas técnicas da pesquisa bibliográfica têm sido utilizadas em outros textos, publicados em periódicos e eventos científicos.

\section{REFERÊNCIAS}

ANDREOLA. B. A. Pedagogia do oprimido: um projeto coletivo. In: FREIRE, A. M. A. (org.). A Pedagogia da Libertação em Paulo Freire. São Paulo: Editora UNESP, 2001. p. 43-46

APPLE, M. W. Paulo Freire e as tarefas do estudioso/ativista crítico na educação. In: APPLE, M. W. A educação pode mudar a sociedade? Petrópolis: Vozes, 2017. p. 47-82.

AROEIRA, K. P. Estágio supervisionado: possibilidades para uma formação com vínculos colaborativos entre a universidade e a escola. In: ALMEIDA, M. I. de; PIMENTA, S. G. (orgs.). Estágios supervisionados na formação docente. São Paulo: Cortez, 2014. P. 113151. 
PAULA, L. C. de

ARROYO, M. G. Paulo Freire em tempos de exclusão. In: FREIRE, A. M. A. (org.). A

Pedagogia da Libertação em Paulo Freire. São Paulo: Editora UNESP, 2001. p. 163-170.

DAMBROSKI, C.; PAULA, L. C. de. A importância do estágio curricular supervisionado para a formação docente no curso de Pedagogia da Universidade Estadual de Ponta Grossa. 2016. 91 f. Trabalho de Conclusão de Curso em Educação - Universidade Estadual de Ponta Grossa, Ponta Grossa, Paraná.

FAZENDA, I. C. A. O papel do estágio nos cursos de formação de professores. In: PICONEZ, S. C. B. (coord.). A prática de ensino e o estágio supervisionado. Campinas, SP: Papirus, 2001. p. 53-62.

FIORI, E. M. Aprender a dizer a sua palavra. In: FREIRE, P. Pedagogia do oprimido. Rio de Janeiro: Paz e Terra, 2004. p. 9-21.

FREIRE, P. A importância do ato de ler. em três artigos que se completam. São Paulo: Cortez, 2015.

FREIRE, P. À sombra desta mangueira. São Paulo: Olho d'Água, 2005.

FREIRE, P. Pedagogia da autonomia. Rio de Janeiro: Paz e Terra, 2014.

FREIRE, P. Pedagogia da esperança. Um reencontro com a Pedagogia do oprimido. Rio de Janeiro: Paz e Terra, 2003.

FREIRE, P. Pedagogia do oprimido. Rio de Janeiro: Paz e Terra, 2004.

FREIRE, P.; SHOR, I. Medo e ousadia. Cotidiano do professor. Rio de Janeiro: Paz e Terra, 2003.

LIMA, T. C. S. de. \& MIOTO, R. C. T. Procedimentos Metodológicos na construção do conhecimento científico: a pesquisa bibliográfica. Revista Katál. Florianópolis, v. 10, 2007.

MINAYO, M. C. de S. O desafio do conhecimento. São Paulo/ Rio de Janeiro: HucitecAbrasco, 1994.

PICONEZ, S. C. B. A prática de ensino e o estágio supervisionado: a aproximação da realidade escolar e a prática da reflexão. In: PICONEZ, Stela C. Bertholo. (coord.). A prática de ensino e o estágio supervisionado. Campinas, SP: Papirus, 2001. p. 15-38.

PIMENTA, S. G.; LIMA, M. S. L. Estágio e docência. São Paulo: Cortez, 2011.

SALVADOR, A. D. Métodos e técnicas de pesquisa bibliográfica. Porto Alegre: Sulina, 1978. 
SILVA, I. de B. S.; PAULA, L. C. de. O Estágio curricular Supervisionado em Docência na Educação Infantil sob o olhar das(os) acadêmicas(os) de Pedagogia da UEPG, das educadoras de um CMEI de Ponta Grossa e das professoras orientadoras de estágio da UEPG. 2016. 112 f. Trabalho de Conclusão de Curso em Educação - Universidade Estadual de Ponta Grossa, Ponta Grossa, Paraná.

Lucimara Cristina de Paula: Professora Adjunta do Departamento de Pedagogia DEPED do Setor de Ciências Humanas, Letras e Artes da Universidade Estadual de Ponta Grossa.

E-mail: lucrispaula@gmail.com

Este periódico utiliza a licença Creative Commons Attribution 3.0, para periódicos de acesso aberto (Open Archives Iniciative - OAI). 